\title{
Determination of Earth Pressure and Displacement of the Retaining Structure According to the Eurocode 7-1
}

\author{
Eugeniusz Dembicki ${ }^{1}$, Bogdan Rymsza ${ }^{2}$ \\ ${ }^{1}$ Faculty of Civil and Environmental Engineering, Gdańsk University of Technology, Gdańsk, Poland \\ ${ }^{2}$ Faculty of Civil Engineering, Warsaw University of Technology, Warsaw, Poland \\ E-mails: ' ${ }^{2}$ demb@pg.gda.pl (corresponding author); ${ }^{2}$ bogdan.rymsza@wp.pl
}

\begin{abstract}
Comparative analysis of standard guidelines and findings given in EC7-1 and in Polish Standard PN-83/B-03010. Discussed guidelines concerning active and passive earth pressure as well as at rest pressure state. Wall displacement causing limit states of earth pressure and resistance. Interactive assumptions concerning intermediate earth pressure and resistance values. Conclusions and final remarks.
\end{abstract}

Keywords: active and passive earth pressure, at rest state, Eurocode EC7-1, retaining wall stability and displacement.

Conference topic: Design experiences and theoretical solutions.

\section{Introduction}

For the design of retaining structures according to the Eurocode 7-1 some questionable interpretations appear. The questionable are certain general rules given in section 9 (EN 1997-1:2004 / section 9) and above all uncomplementary formulas and calculation examples in corrected version of Annex C (EN 1997-1:2009 / AC). Detail remarks with the validation of questions were presented on the country forum in the paper (Dembicki, Rymsza 2015). In conducted comparative analysis it was referred to literature data and the indications in preceding Polish Standard "Retaining Walls" which was edited before some years by authors of this paper. Normalisation problems are broadly discussed at the international conferences and workshops. It may be supposed that also short analysis of earth pressure calculation on the base of the Eurocode principles will be interesting for participants of the $13^{\text {th }}$ BSG Conference.
Taking into account the communicativeness enlargement of this paper the analysis is preceded by some elucidation of interdependence between earth pressure and displacement of a retaining structure.

On the base of the Coulomb's classic theory (1773) and on the Rankine's assumptions (1857) it is possible to determine only extreme values of earth pressure:

$-E_{\min }=E_{a}-$ active pressure (minimal total earth pressure on the retaining structure),

$-E_{\max }=E_{p}-$ passive pressure (possible maximal earth pressure).

Discounting quantitative differences resulting from distinctive assumptions Coulomb's theory (limit balance of rigid soil wedges) and Rankine's theory (limit state of stress when plastic slides of soil appear), must be taken into account one identity presumption: rigidplastic soil model (Fig. 1a, line 2).
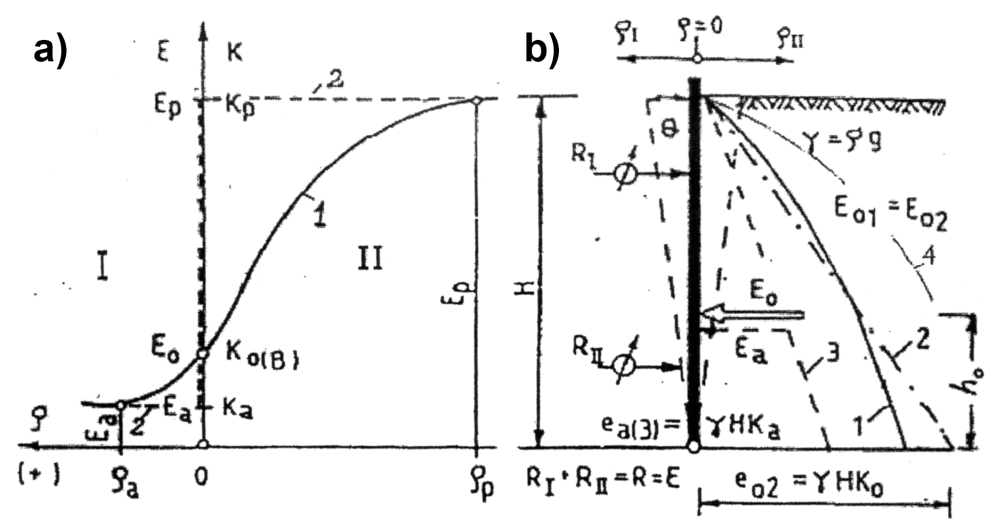

Fig. 1. Interdependence between earth pressure and displacements of the retaining wall

a) variability of earth pressure ( 1 -real dependence, 2 - rigid-plastic soil model) b) unit pressure distribution and the model wall in test carried on by K. Terzaghi (Terzaghi 1934) ( 1 - earth pressure at rest for $\rho=0,2$ - comparative linear distribution,

$$
\left.3 \text { - active pressure } e_{a} \leq e\left(\rho_{\mathrm{I}}\right)<e_{0}, 4 \text { - passive pressure } e_{0} \leq e\left(\rho_{\mathrm{II}}\right)<e_{p}\right)
$$


Solution presented by Coulomb concerns the basic case: vertical retaining wall with smooth surface $(\alpha=0$, $\delta=0)$, unloaded horizontal backfill $(\beta=0, q=0)$, noncohesive soil $(\gamma>0, \varphi>0, c=0)$. For this case following relationships are received:

$$
\begin{aligned}
& E_{a}=0,5 \gamma H^{2} K_{a C} ; \\
& E_{p}=0,5 \gamma H^{2} K_{p C},
\end{aligned}
$$

where (Fig. 1b): $\gamma=\rho \mathrm{g}-$ soil bulk density; $H$ - wall height; $\varphi$ - soil internal friction angle; $K_{a C}=\tan ^{2}\left(45^{\circ}-\right.$ $\varphi / 2)$ - active pressure coefficient; $K_{p C}=\tan ^{2}\left(45^{\circ}+\varphi / 2\right)$ - passive pressure coefficient.

In the designations of pressure coefficients index " $C$ " is added, which complies with the scheme of wall considered by Coulomb. In the later years on the base of this theory were presented different generalised solutions (Poncelet, Blum, Müller-Breslau and others). These solutions and generalised pressure coefficients $K_{a ; p}=\mathrm{F}_{a ; p}(\varphi, \delta, \alpha, \beta)$ are given in the literature (Dembicki 1979; Kézdi 1974; Weissenbach 1975). There were also formed the generalised calculation methods applied for active and passive earth pressures determination, based on the plasticity theory in which special meaning have Sokolovski's and Caquot-Kérisel's solutions analysed in Dembicki's works (Biernatowski et al. 1987; Dembicki 1979).

The interdependence of earth pressure and retaining wall displacements in range $E_{a} \leq E(\rho) \leq E_{p}$ (Fig. 1a, line 1) was noticed by K. Terzaghi (1934-35). He carried out broad investigations of pressure changes in model and half-technical scale (Terzaghi 1934). Terzaghi defined also earth pressure at rest as the state of ground pressure for a rigid and unyielding retaining wall, $E_{0}=E(\rho=0)$. Analysing the scheme and value of measured forces $R_{\mathrm{I}}, R_{\mathrm{II}}$, he pointed out that distribution of the unit earth pressure at rest $e_{0}(h)$ is curvilinear (Fig. 1b, line 1). It complies with the coefficient of resultant force position $\eta_{0}=h_{0}: H=0.33 \div 0,42$, which value is the bigger as the higher is backfill compaction. $\mathrm{K}$. Terzaghi determined also retaining wall displacements $\rho_{a}, \rho_{p}$, which assure the inception of pressure limit states $E_{a}, E_{p}$ (Fig. 1a) and indicated that they depend on soil kind and state and wall motion scheme (in the comparative investigations were varied $\rho=\theta$ - rotation angle with regard to lower edge and $\rho=\Delta-$ parallel displacement).

K. Terzaghi and later investigators (R. B. Peck, H. Duddeck, A. Kézdi, Weissenbach and others) for curvilinear pressure distribution accepted in comparative analysis substitute (resultant) pressure coefficient of the earth pressure at rest (Fig. 1b, lines 1,2):

$$
K_{0}=\frac{E_{0}}{0,5 \gamma H^{2}} \text {. }
$$

Analysing in situ stress state and accepting strain criterion $\varepsilon_{h}=0$, at rest pressure coefficient is determined as the ratio of horizontal to vertical effective stresses:

$$
K_{0}=\sigma_{h}^{\prime}: \sigma_{v}^{\prime} .
$$

The value $K_{0}$ (4) may be determined directly on the base of field or laboratory investigations (Rymsza 1997). This coefficient is often determined by correlation method, where simplified Jáky's formula given for sands $(\varphi>0, c=0)$ and afterwards generalised for cohesive soils normally consolidated $(N C)$ with assumption $\varphi=\varphi^{\prime}$ is usually used (Dembicki, Rymsza 2015; Kézdi 1974; Weissenbach 1975):

$$
K_{0-N C}=1-\sin \varphi .
$$

For preconsolidated soils (OC) Schmidt's formula is most often used (Mayne, Kulhawy 1982; Rymsza 2013; Seed, Duncan 1986):

$$
K_{0-O C}=\left(1-\sin \varphi^{\prime}\right) O C R^{\sin \varphi^{\prime}},
$$

where $O C R=\sigma_{v p}^{\prime}: \sigma_{v 0}-$ preconsolidation index presenting the ratio of effective vertical stresses in the phase of soil overload to actual primary stresses.

\section{Analysis of Eurocode indications and requirements}

Indications concerning limit values of active and passive earth pressure

According to the previous Annex C (Eurocode 7-1/ Annex C: 2004) the limit values of earth pressure on a vertical wall $(\alpha=0)$, caused by ground with weight density $\gamma$, angle of internal friction $\varphi$ and soil cohesion $c$ in case of uniform surface loading $q$ should be calculated as follows:

$$
\begin{aligned}
& \sigma_{a}(z)=K_{a}(\gamma z+q)-2 c \sqrt{K_{a}} ; \\
& \sigma_{p}(z)=K_{p}(\gamma z+q)+2 c \sqrt{K_{p}},
\end{aligned}
$$

where:

$\sigma_{a}(z)=e_{a}(z)-$ the stress normal to the wall at depth $z$ in active limit state (unit active earth pressure);

$K_{a}=F_{a}(\varphi, \delta, \beta)-$ the coefficient of horizontal active earth pressure dependent on the internal friction angle $\varphi$, the shearing resistance angle between ground and wall $\delta$ and the slope angle of ground surface $\beta$, taken from nomograms (an example Fig. 2a);

$\sigma_{p}(z)=e_{p}(z)$ - the stress normal to the wall at depth $z$ in passive limit state (unit passive earth pressure);

$K_{p}=F_{p}(\varphi, \delta, \beta)-$ the coefficient of horizontal passive earth pressure dependent on the parameters $\varphi, \delta, \beta$ (as above), taken from nomograms (an example Fig. 2b).

Equations (7) and (8) could be applied either in terms of total or effective stress. Besides horizontal earth pressure $e_{a ; p}=\sigma_{a ; p}$ the stress tangential to the wall $\tau_{a, n}=\sigma_{a ; p} \tan \delta+a$, dependent on the adhesion $a$ should be considered. These indications were similar to the literature data (Dembicki 1979; Kézdi 1974; Recommendations on Excavations 2003). However in the Annex C 

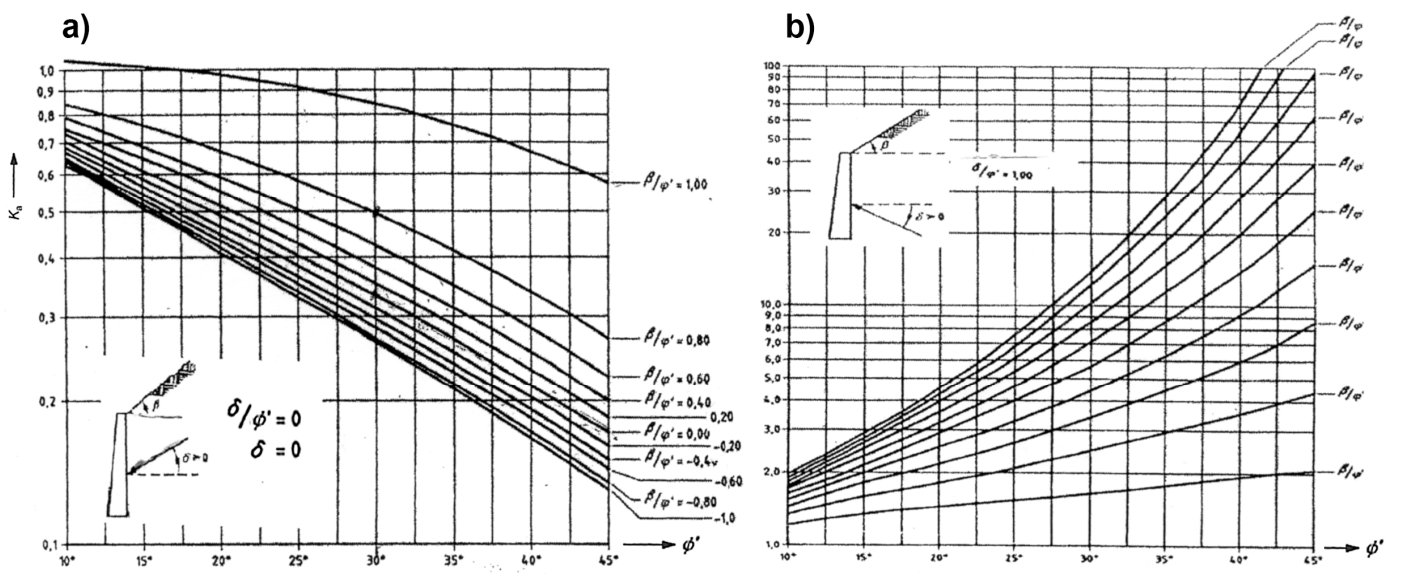

Fig. 2. Coefficients of effective earth pressure (horizontal component) with inclined retained surface acc. to AC (Eurocode 7-1/Annex C: 2004)

a) coefficient of active pressure $K_{a}$ for $\delta / \varphi^{\prime}=0$, b) coefficient of passive pressure $K_{p}$ for $\delta / \varphi^{\prime}=1$

(Eurocode 7-1/Annex C: 2004) are not given formulas, which determine resultant forces of earth pressure $E_{a}, E_{p}$. It should be noticed that in calculating of these forces big interpretation discrepancies can appear.

There is lacking of these formulas also in the corrected version of Annex C (Eurocode 7-1/AC: 2009), although are introduced here essential changes in analytical terms of unit limit earth pressures:

$$
\begin{aligned}
& \sigma_{a}(z)=K_{a}\left[\int \gamma d z+q-u\right]+u-c K_{a c} \\
& \sigma_{p}(z)=K_{p}\left[\int \gamma d z+q-u\right]+u-c K_{p c},
\end{aligned}
$$

where:

$\gamma, \varphi, c, q, a, z-$ symbols used for Eqs (7), (8);

$\sigma_{a}(z)=e_{a}(z)$ - the limit active earth pressure, when total stress normal to the wall is considered;

$K_{a}$ - the coefficient of effective horizontal active earth pressure taken from nomograms $K_{a}(\varphi, \delta, \beta)(\mathrm{Eu}-$ rocode 7-1/Annex C: 2004; AC: 2009) (an example - Fig. 2a);

$K_{a c}=2 \sqrt{K_{a}(1+a / c)} \leq 2,56 \sqrt{K_{a}}$ - the coefficient of cohesion influence on active earth pressure.

$\sigma_{\mathrm{p}}(z)=e_{p}(z)$ - limit passive earth pressure when total stress, normal to the wall is considered,

$K_{p}$ - the coefficient of effective horizontal passive earth pressure taken from nomograms $K_{p}(\varphi, \delta, \beta)(\mathrm{Eu}-$ rocode 7-1/Annex C: 2004; AC: 2009) (an example - Fig. 2b);

$K_{p c}=2 \sqrt{K_{p}(1+a / c)} \leq 2,56 \sqrt{K_{p}}$ - the coefficient of cohesion influence on passive earth pressure.

In the application account it was indicated (Eurocode 7-1/AC: 2009):

- for drained soil, $K_{a}$ and $K_{p}$ are the functions of friction angle $\left(\varphi^{\prime}\right)$ and effective cohesion $\left(c^{\prime}\right)$,

- for undrained soil $K_{a}=K_{p}=1$ and $c=c_{u}$ (where $c_{u}$ - the undrained soil strength),
- values of the effective earth pressure coefficients may be taken from nomograms in AC: 2009 (the same nomograms were given in the previous Annex C: 2004 - the author's comment).

Analysing Eqs (9), (10) and connected Eurocode indications it is possible to present the following remarks and questions:

1. In the specifications of used symbols and in the application description it was not explained the meaning of $u$ parameter. Accepting that it means pore water pressure following questions occur:

- Is it the water pressure acting on the wall resulting from local ground - water conditions?

- Or is it the pore water pressure induced on the surface slide when limit shear state occurs (for instance when loading $q$ is growing)?

Taking into account the above ambiguity of " $u$ " parameter it is difficult to estimate the correctness of Eqs (9), (10) vs (7), (8). The fact must be also considered that the acceptation the same pressure coefficients $K_{a ; p}=K_{a ; p}^{\prime}$ with reference to the total stresses $\sigma_{v}=\gamma z$ and effective stresses $\sigma_{v}^{\prime}=\sigma_{v}-u$ causes the divergence of system $e_{a ; p}=\sigma_{a ; p}=\gamma z K_{a ; p} \neq(\gamma z-u) K_{a ; p}^{\prime}+u$.

2. Eurocode nomograms of $K_{a}, K_{p}$ coefficients (given examples - Fig. 2a, b) were determined assuming plane surfaces of slide. In a case of active earth pressure the error resulting from this assumption is rather small $\pm 5 \div 10 \%$ (Dembicki 1979; Dembicki, Rymsza 2015; Recommendations on Excavations 2003). However an appliance of limit passive pressure $E_{p}\left[K_{p}(\varphi, \delta, \beta)\right]$ according to Eurocode indications may be very dangerous. It is because for big angle values $\varphi^{\prime}$ and $\delta$ the $K_{p}$ values taken from nomogram are totally unreal (see Fig. 2b). For these $K_{p}$ values calculated limit passive earth pressure may be even $2 \div 3$ times bigger than real passive force $E_{p-r}$. Explaining the relation $E_{p-r}<E_{p}\left(K_{p}\right)$ attention must be paid that in real 
conditions the sliding of displaced ground takes place on the "energetically easier" curvilinear surface. Then in design calculations Caquot-Kérisel's coefficients $\left(K_{p-C K}<K_{p}\right)$ determined for curvilinear sliding and presented in literature (Biernatowski et al. 1987; Dembicki 1979; Kézdi 1974) or global corrective coefficients $\eta(\varphi, \delta, \beta)=E_{p-r}: E_{p}\left(K_{p}\right)=$ $0,3 \div 1,0$ given in Polish Standard $(\mathrm{PN}-83 / \mathrm{B}-$ 03010 1983) should be accepted.

3 . The wall - ground interface parameter $\delta$, characterising the roughness existing between the soil and a wall, has great influence on the calculated passive earth pressure. In case of $\Delta>0,5 \varphi$ this value is dangerously overestimated $\left[E_{p, d}\left(\delta_{d}\right)>\right.$ $\left.E_{p-r}\left(\delta_{\mathrm{k}}\right)\right]$. Hence, the EC7-1 indication $\delta_{d}=k \varphi_{c v, d}$ : with comment "For concrete cast against soil, a value of $k=1,0$ may be assumed" (Eurocode 7$1 /$ Section 9, p. 9.5.1) is ununderstood.

4. Eurocode Eqs (9), (10) are fixing the value and distribution of unit limit pressures. However they do not give any indications how to calculate resultant forces, what in the case of active pressure $E_{a}$ $\left[\sigma_{\mathrm{a}}(z, \gamma, q, u, c), H\right]$ for cohesive soils is simply incomprehensible. It must be paid attention that according Eq. (9) (where later for simplification $q$ $=0, u=0)$ in upper wall area to depth $z_{I}=h_{c}=$ $c K_{c}: \gamma K_{a}$ should occur extension stresses $e_{a}=$ $\sigma_{a}(\gamma, z, c)<0$. So, to estimate the active earth pressure $E_{a}$ three calculation schemes are possible:

- The determination resultant force $E_{a 1}$ taking into account the stresses $\sigma_{a}(z)<0$ in the zone $0<z \leq h_{c}$ and the stresses $\sigma_{a}(z)>0$ in the zone $h_{c}<z \leq H$ (trapezoidal resultant diagram of unit pressure).

- Accepting in the zone $z_{I}$ "zero pressure" state $e_{a}=$ 0 (assuming possibility creation of contractive fissures), one can calculate the force $E_{a 2}\left(\sigma_{a}, z_{I I}\right)>E_{a 1}$ according to stresses $\sigma_{a}>0$ in the lower zone $z_{I I}=$ $H-h_{c}$.

- Accepting in the upper wall zone $0<z \leq h_{c}$ minimal unit pressure $e_{a}(z)=0,2 \gamma z>0$ in compliance with Weissenbach's recommendation (Weissenbach 1975) and in the lower zone $h_{c}<z \leq H$ the stresses $\sigma_{a}(z)>0$ according to the formula (9) one can calculate the force $E_{a 3}>E_{a 2}$.

With large soil cohesion and comparatively low retaining wall $H \leq 3 h_{c}$ the divergence in estimation of active pressure value may be significant $\left(E_{a 3}: E_{a 1}=2 \div 3\right)$. The question is as follows: what is the sense to place detailed demands or general orders - for instance (Eurocode 7-1 / Section 9): the necessity of exact determination of water volume weight (p. 9.3.1.4) or an order to analyse the influence of temperature changes on the retaining structure design (p. 9.3.1.8) while some essential indications which determine calculation accuracy are omitted.

5. Eurocode indications for undrained soils recommending to accept $K_{a}=K_{p}=1$ are incomprehensible and wake following reservations:
- The statement that an embedded wall is built in undrained soil conditions (for instance in stiff or firm clays) does not prove that cohesive medium is deprived of friction (accepting $K_{a}=K_{p}=1$ is equivalent with assumption $\varphi_{u}=0-$ compare the coefficients $K_{a C}(1)$ and $K_{p C}(2)$ ).

- In case of pore water pressure arousing $u>0$ - for example, as a result of counter - ties or anchors performing either surface loading enlargement for arbitrary acceptance $K_{a}=K_{p}=1$ unreal loading differentiations are received: $1.5 \div 2$ times active earth pressure growth and $2 \div 3$ times passive earth pressure reduction. The acceptation of this indication will guide to irrational (uneconomic) design.

6. Some Eurocode notations are erroneous or incomprehensible and must be corrected, for instance:

- In the point C.1 (2) (Eurocode 7-1/AC: 2009) erroneously was confirmed, that for drained soil, $K_{a}$ and $K_{p}$ are functions of the shearing resistance angle $\varphi^{\prime}$ and effective cohesion $c^{\prime}$. These coefficients are functions of the $\varphi^{\prime}, \beta, \delta$ angles and in any way do not depend on cohesive resistance (see Fig. 2a, b).

- The inclusion to Eqs (9), (10) integral calculus wakes the surprise, because $\int \gamma d z=\gamma z$ (needless pseudoscience).

- For the formulas (9) and (10) are given limitations relating to the adhesion " $a$ " in following notation $K_{x c}=2 \sqrt{K_{x}(1+a / c)} \leq 2,56 \sqrt{K_{x}}$, where respectively $K_{x}=K_{a}, K_{p}$; Solving this inequality may be received more simple condition $a / c \leq 0,64$, where strikes the precision of given limitations.

- In the diagram $K_{a}(\varphi, \beta)$ for the smooth wall $(\delta=0$ - Fig. 2a) was indicated incorrectly the direction of earth pressure force $E_{a}(\delta>0)$.

\section{The basic values of earth pressure at rest}

For the proper determination of range variability of earth pressure $E_{a} \leq E_{I}(\rho) \leq E_{0}$ and the range of possible passive earth pressure $E_{0}<E_{I I}(\rho) \leq E_{p}$ necessary is the knowledge of the basic (initial) earth pressure at rest value $E(\rho=0)=E_{0}$ (Fig. 1). Eurocode indications in relation to the at rest pressure $E_{0}$ are limited to three hints ((Eurocode 7-1 / Section 9), p. 9.5.2):

-For normally consolidated soil at rest conditions should be accepted if the movement of the retaining structure is less than $5 \cdot 10^{-4} \cdot h$.

- For horizontal ground surface the at rest pressure coefficient $K_{0}$ should be determined from:

$$
K_{0}=\left(1-\sin \varphi^{\prime}\right) \sqrt{O C R},
$$

where: $O C R$ - overconsolidated ratio explained for the Eq. (6); if $O C R=1, K_{0}=K_{0-N C}$.

-For the ground slopes upwards from the wall at an angle $\beta \leq \varphi^{\prime}$, the direction of resulting force $E_{0}$ should be assumed parallel to the ground (backfill) surface, while horizontal component of the effec- 
tive earth pressure $\sigma_{h 0}^{\prime}=e_{0}^{\prime}$ may be related to the effective overburden pressure $\sigma_{v 0}^{\prime}$ by the ratio $K_{0 ; \beta}$, where

$$
K_{0 ; \beta}=K_{0}(1+\sin \beta) .
$$

Though in Eurocode EC7-1 the earth pressure at rest is identified with stress state in-situ, in p. 9.5.5 ("compaction effects" - Eurocode 7-1 / Section 9) it is stated that in the determination of earth pressures acting behind the wall must be taken into account the additional pressures generated by any placing of backfill and the procedures adopted for its compaction. The additional pressure acts normally on the upper part of the wall and depends on the applied compaction energy, the thickness of the compacted layers and the travel pattern of the compaction plant. At the end it was stated as follows (9.5.5. (2) P): "Appropriate compaction procedures shall be specified with the aim of avoiding excessive additional earth pressures which may lead to unacceptable movements". However it is not given closer, more précising indications specifying these recommendations, as well lacking are calculation formulas enabling the estimation of this "additional earth pressure".

To elucidate this problem the distribution of compacted backfill pressure acting on a rigid and unyielding wall $(\rho=0)$ is presented (Fig. 3a). The scheme is based on a concept of compaction - induced horizontal stresses elaborated by Duncan and Seed (Seed, Duncan 1986) with some later modifications suggested by Rymsza (Rymsza 1997, 2013). Backfilling of cohesionless soil $(\gamma, \varphi, c=0, u=0)$ is realised in technological - repeated cycles "Loading - Unloading - Reloading" (L-U-R phases, Fig $3 b)$ for layers $\Delta H_{i} \approx$ const $(i=1,2, \ldots, n)$, where cyclic application and removal of surcharge $q$ given by compaction machine is treated as mechanical overconsolidation of soil. In general case three zones of earth pressure are obtained.

In upper zone I during the L-phase, peak horizontal stresses $\left[\sigma_{h i}\left(q, z_{i}, x_{i}\right)\right]$ max can be determined (Fig. 3a - lines "1-i", an envelope of curves family "1-i" - line 2). In the U-phase ( $q=0$, full vertical distressing to $\sigma_{\mathrm{v} 0}=\gamma z_{i}$ ) two partial lateral decompressions are followed: quasi-elastic relaxation in accordance with the Eq. (6) or (11) (the residual stress state $\sigma_{h r}=\sigma_{h \max }-\Delta \sigma_{h e}$, line 3) and plastic relaxation due to maximum possible stresses to be retained $\left(\sigma_{h 0}=e_{0}=\sigma_{v 0} K_{I}-\right.$ line 4-I, where $\mathrm{K}_{0-N C}<$ $K_{1-O C} \approx 1<K_{p}$ (Rymsza 1997; 2013).

- In transitive zone II elastic impulses $\Delta \sigma_{v, h}\left(q, z_{i}\right)$ caused in layers $i=4 \div 7$ during compaction of the upper layer $i=1$ disappear with the depth $z_{i}$. According to the R-phase (stress path E-L, Fig. 3b-II) unit earth pressure should be taken as $e_{0 \mathrm{II}}=\sigma_{h R}$ (Fig. 3a, line 4-II).
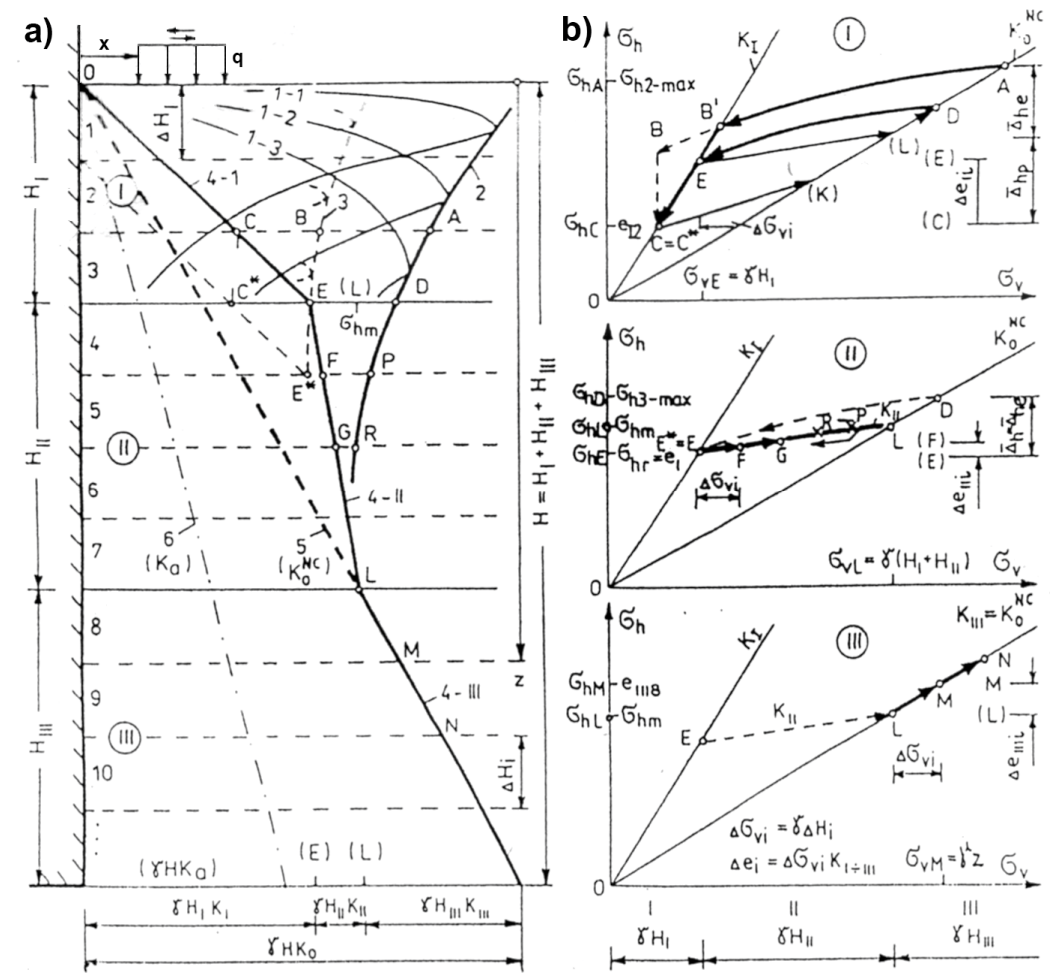

Fig. 3. Computational scheme of earth pressure at rest for granular backfill compacted in layers:

a) horizontal stress distributions in respective "Loading - Unloading - Reloading" phases (lines $1 \div 6$ explained in the paper)

b) stress paths $\sigma_{h}$ vs $\sigma_{v}$ in the L-U-R phases corresponding with earth pressure zones I $\div$ III 
- In zone III $\left(z>H_{\mathrm{I}}+H_{\mathrm{II}}, i \geq 8\right)$ the overburden stresses $\sigma_{v 0}=\gamma z$ and $\sigma_{h 0}\left(\sigma_{v 0}, \mathrm{~K}_{0-N C}\right)$ are bigger than „memorised stresses" coded previously at lower level of backfill. Considering the VL-state (virgin loading), the linear distribution of the earth pressure at rest $e_{0 I I I}=\gamma z K_{0-N C}$ should be taken into account (Fig. 3a - line 4-III respectively to line 5).

Additional earth pressure from backfill compaction can be graphically interpreted as the area $\triangle \mathrm{OEL}$ (Fig. $3 \mathrm{a}$ - field bordered by the lines 4-I, II; 5). The closer analysis of this problem was presented in the papers (Rymsza 1997, 2013). Here the problem is confined to general showing in a certain light a computation algorithm and to pay attention for some Eurocode commands as in the following case: "it must be taken into account additional pressure generated due to the fill compaction" are simply formulated but without closer indications are very difficult for detailed realisation.

\section{Wall displacements conditioning the appearance of limit states of active and passive earth pressures}

The relative values of wall displacement: $v_{a} / h=\bar{\rho}_{a}-$ needed to appear the limit active pressure $E_{a}$; $v_{p} / h=\bar{\rho}_{p}-$ necessary to mobilise limit passive pressure $E_{p}$, specified for non-cohesive soils with regard four kinematic schemes are shown in the Table 1 and Table 2 (Eurocode 7-1/AC: 2009). The indications relating to the creation of limit active pressure do not wake any restrictions; they are convergent with literature data (Biernatowski et al. 1987; Kézdi 1974; Weissenbach 1975). Differently, $v_{p} / h$ values appear to be too high, especially with reference to displacement schemes " 1 " and " 2 ". The basic objection relating to discussed here indications (Table 2) is fact that they appointed for noncohesive soils only. The question is: how in the design of embedded walls should be treated cohesive soils?



Fig. 4. Displacement of a retaining wall needed to mobilise limit active $\left(\rho_{a}\right)$ and/or passive $\left(\rho_{p}\right)$ earth pressure (acc. to Polish Standard (PN-83/B-03010 1983))

It is mentioned that in the Polish Standard (PN-83/B-03010 1983) were given generalised indications conditioning displacement values $\rho_{a, p}(\varphi, h)$ : $h=v_{a, p}: h$ with the angle of soil internal friction $\varphi$ and with the wall height $h$ in the zone of active or passive pressure (Fig. 4). Linking to the comparative investigations and literature data, the relation $\rho_{p}=10 \rho_{a}$ was

Table 1. Ratios $v_{a} / h$ for non-cohesive soils (EC 7-1/AC:2009)

\begin{tabular}{c|c|c}
\hline $\begin{array}{c}\text { Kind of wall } \\
\text { movement }\end{array}$ & $\begin{array}{c}v_{a} / h \\
\text { loose soil } \\
{[\%]}\end{array}$ & $\begin{array}{c}v_{a} / h \\
\text { dense soil } \\
{[\%]}\end{array}$ \\
\hline (1) & 0.4 to 0.5 & 0.1 to 0.2 \\
\hline (2) & & \\
\hline
\end{tabular}

where:

$v_{a}$ is the wall displacement to mobilise active earth pressure $h$ is the height of the wall

Table 2. Ratios $v_{p} / h$ and $v / h$ for $0.5 \sigma_{p}$ for non-cohesive soils (EC 7-1/AC:2009)

\begin{tabular}{|c|c|c|}
\hline $\begin{array}{l}\text { Kind of wall } \\
\text { movement }\end{array}$ & $\begin{array}{c}v_{p} / h \\
\left(v / h \text { for } 0.5 \sigma_{\mathrm{p}}\right) \\
{[\%]}\end{array}$ & $\begin{array}{c}v_{p} / h \\
\left(v / h \text { for } 0.5 \sigma_{\mathrm{p}}\right) \\
{[\%]}\end{array}$ \\
\hline & loose soil & dense soil \\
\hline 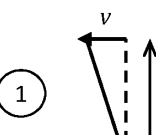 & $\begin{array}{c}7 \text { to } 25 \\
\text { (1.5 to } 4.0)\end{array}$ & $\begin{array}{c}5 \text { to } 10 \\
\text { (1.1 to } 2.0)\end{array}$ \\
\hline  & $\begin{array}{c}5 \div 10 \\
(0.9 \div 1.5)\end{array}$ & $\begin{array}{c}3 \div 6 \\
(0.5 \div 1.0)\end{array}$ \\
\hline$L_{v} \begin{array}{c}1 \\
1 \\
1 \\
1\end{array}$ & $\begin{array}{c}6 \div 15 \\
(1.0 \div 1.5)\end{array}$ & $\begin{array}{c}5 \div 6 \\
(0.5 \div 1.3)\end{array}$ \\
\hline
\end{tabular}

where:

$v$ is the wall displacement

$v_{p}$ is the wall displacement to mobilise passive earth pressure

$h$ is the height of the wall

$\sigma_{p}$ is fully mobilised passive earth pressure 


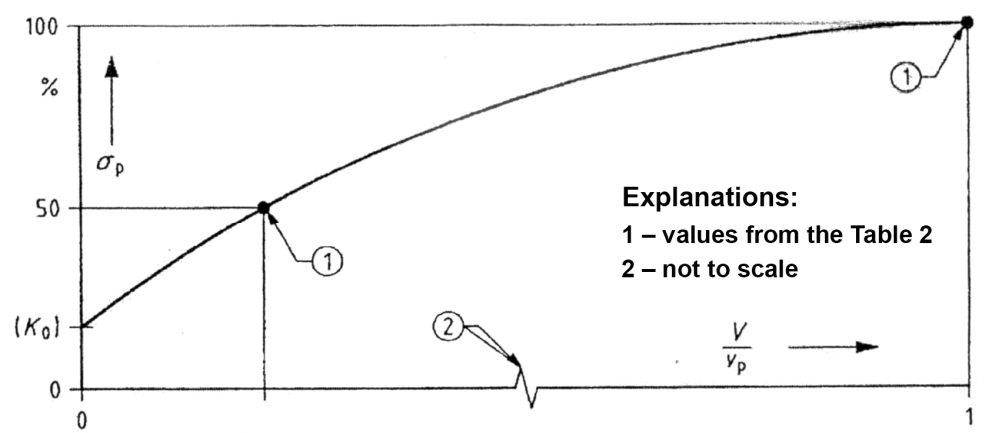

Fig. 5. Mobilisation of effective passive earth pressure of non-cohesive soil versus wall displacement $v / v_{p}$ (acc. To EC7-1/AC (Eurocode 7-1/AC: 2009))

accepted. The values $\rho_{a, p}$ were given for comparative wall angle displacements $\rho(\theta)=\rho$ pointing out that for parallel displacements $\rho(\Delta)$ necessary is to accept $\rho_{a, p}(\Delta)=0,5 \rho_{a, p}$.

\section{Interactive dependencies referred to intermediate active and passive pressure values}

The design of retaining structures shall be checked at the ultimate limit state (ULS) for the all design situations specified in the Eurocode 7-1, p. 9.3.3. In calculations for ULS the designed limit forces should be determined, for example: $E_{a, d}=E_{a} \cdot \gamma_{F}-$ as action, $E_{p, d}=E_{p}: \gamma_{R}-$ as resistance, where partial safety factors $\gamma_{F ; R}>1$ are established in the EC 7-1/AA.

In some cases, for example to estimate settlements and/or lateral displacements of a retaining wall serviceability limit state (SLS) is also considered. To analyse SLS conditions the knowledge of real forces acting in static equilibrium state is necessary (Rymsza 1997). To calculate the forces $E_{\mathrm{I}}(\rho), E_{\mathrm{II}}(\rho)$ the interaction model taking into account the interdependence between earth pressure and construction displacement has to be considered. Eurocode indications concerning the active and passive earth pressure variability are following (Eurocode 7-1/AC: 2009):

- In the calculation of intermediate earth pressure in the range $E_{a}\left(v_{a}\right) \leq E_{\mathrm{I}}(\rho=v)<E_{0 \mathrm{I}}$ linear interpolation may be used (p. C.3(3));

- In the calculation of mobilised passive earth pressure for wall displacement $\rho=v$ changing in the range $E_{0 I I}<E_{\text {II }}(\rho=v) \leq E_{p}\left(v_{p}\right)-$ for non-cohesive soils parabolic interpolation, according to Figure 5 should be used (p. C.3(4)).

In relation to these two notices are important:

- Incomprehensible is the limitation of applicational indications, concerning the calculation of intermediate active and/or passive earth pressure values for non-cohesive soils only. The question is in what way should be calculated $E_{\mathrm{I}}$ and $E_{\mathrm{II}}$ values in the case of cohesive soils?

- In Eurocode EC7-1 there is no reference indicating the dependence active and passive earth pressure distribution on the scheme of wall kinematic displacement. These relations are very important, especially in the case of passive earth pressure (Biernatowski et al. 1987; Dembicki 1979; Kézdi 1974; Terzaghi 1934). What is the sense of the differentiation of numeral indications $v_{a} / h$ and $v_{p} / h$ (Table $1 ; 2$ - schemes $1 \div 4$ ) when these differentiations are not taken into account in further analysis?

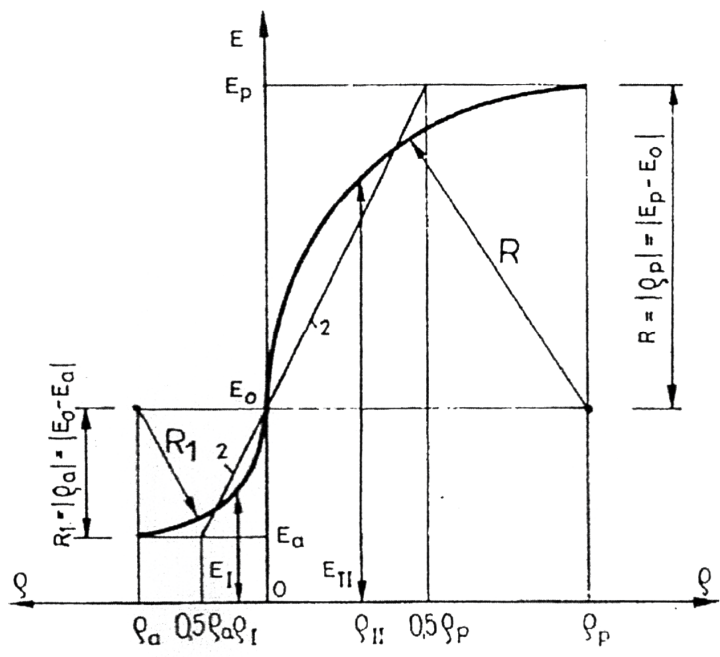

Fig. 6. Variability of earth pressure (acc. to Polish Standard (PN-83/B-03010 1983))

It has to be mentioned that in the Polish Standard (PN-83/B-03010 1983) to calculate the intermediate earth pressure $E_{\mathrm{I}}$ and $E_{\mathrm{II}}$ generalised indications accepted for cohesive and non-cohesive soils were given (Fig. 6). Appointing the ranges of active and passive earth pressure differentiations and imitating these in the isomorphoses scale, where $\left|\rho_{a}\right|=\left|E_{0 \mathrm{I}}-E_{a}\right|$ and $\left|\rho_{p}\right|=\left|E_{p}-E_{0 \mathrm{II}}\right|$ - the values $E_{\mathrm{I}}\left(\rho_{\mathrm{I}}\right)$ and $E_{\mathrm{II}}\left(\rho_{\mathrm{II}}\right)$ are determined graphically in the way presented in Fig. 6. In the Polish Standard the redistribution of unit passive earth pressure according to three schemes of wall displacement was also recommended. 


\section{Final conclusions and comments}

1. Eurocode indications referred to the calculation of limit passive earth pressure $E_{p}$ must be recognised as very dangerous. Using the formulas derived with the assumption plane sliding surfaces with uncritical acceptation in calculations, wall friction angle $\delta_{\max }=\varphi$ and large adhesion $a_{\max } \approx(2 / 3) c$, may lead to considerable enlargement of computed stabilising force $E_{p, d}=E_{p, k}: \gamma_{R}>E_{p-r}$. Besides, taking into account the possibility of lowering limit value of active pressure for cohesive soils (the underestimating of destabilising force $E_{a, d}=\gamma_{F} E_{a, k} \leq$ $\left.E_{a-r}\right)$ - for factor values $\gamma_{R}=1.4$ and $\gamma_{F}=1.35 ; 1.50$ design calculations may lead to erroneous estimation of construction stability.

2 . For the calculation of allowed passive earth pressure $E_{\text {II }}\left(\rho_{\text {all }}\right)<E_{p}$ where $\rho_{\text {all }}<<\rho_{p}=v_{p}$ coefficients $K_{p-C K}$ determined for curvilinear sliding surface or global correctional coefficients $\eta \approx E_{p-r}: E_{p}\left(K_{p}\right)$ $<1$ should be accepted.

3. The indications of Eurocode in many cases are incoherent where the most essential faults are:

- it is lacking the explanation $u$ parameter, which was introduced in the alternated formulas (9), (10);

- it is lacking the indications relating to the retaining wall displacements $v_{a} / h$ and $v_{p} / h$ which condition limit earth pressures for cohesive soils;

- it is lacking the indications due to the distribution of unit passive earth pressure, which must be accepted for particular schemes of wall displacements;

- too general indications referring to the value and distribution of earth pressure at rest in case of compacted backfill.

4. The majority of comments presented in this paper is referred to the indications in Annex C (Eurocode 7-1/AC:2009). It must be paid attention that the indications and data in Eurocode annexes has inquiry character. In the cases when come into existence some ambiguities or objections it is always possible to use other indications taken from literature or experiences.

In the half of 2016 year it is foreseen the beginning of the works connected with the revision of Eurocode EC-7-1;2. Authors of this paper hope that presented here comments and analysis will be useful for new edition of the Eurocode 7-1.

\section{References}

Biernatowski, K.; Dembicki, E.; Dzierżawski, K.; Wolski, W. 1987. Fundamentowanie. Tom 1. Podtoże budowlane [Foundation Engineering. Vol. 1. Subsoil Foundation]. Warszawa: Arkady (in Polish).

Dembicki, E. 1979. Parcie, odpór i nośność gruntu [Active and passive earth pressure and subsoil capacity]. Warszawa: Arkady (in Polish).

Dembicki, E.; Rymsza, B. 2015. Obliczanie parcia gruntu wedlug Eurokodu 7. (Postęp czy regres?) [Calculation of active and passive earth pressure according to the Eurocode 7. (Progress or regress?)], Inżynieria Morska i Geotechnika 36(3) (in Polish).

Kézdi, Á. 1974. Handbook of soil mechanics, Vol. 1. Soil Physics. Budapest: Akadémiai Kiadó.

Mayne, P. W.; Kulhawy, F. H. 1982. $K_{0}-O C R$ Relationships in Soil, Journal of the Geotechnical Engineering, ASCE 6: 851-871.

PN-83/B-03010. Ściany oporowe. Obliczenia statyczne $i$ projektowanie [Retaining walls. Design and static calculations]. PKNMiJ, 1983 (Polish standard) (in Polish).

PN-EN 1997-1:2004. Eurocode 7-1. Geotechnical design. General rules.

Eurocode 7-1 / Section 9. Retaining structures.

Eurocode 7-1 / Annex C: 2004. Sample procedures to determine limit values of earth pressures on vertical walls.

Eurocode 7-1 / AC: 2009 (corrected version of Annex C). Sample procedures to determine earth pressures.

Recommendations on Excavations. 2003. Berlin: Ernst \& Sohn.

Rymsza, B. 1997. Determination of loading and displacements of the backfill retaining wall due to soil-structure interaction, in Proceedings of XIV International Conference on SMFE, 1997, Hamburg, Germany, 2: 12451248.

Rymsza, B. 2013. Współczynnik parcia spoczynkowego gruntu przy warstwowym zageszczeniu zasypki [The coefficient at rest earth pressure for backfill compacted in layers], Acta Scientiarum Polonorum - Architectura 12(3): 8597.

Seed, R. B.; Duncan, J. M. 1986. FE Analyses: CompactionInduced Stresses and Deformations, Journal of the Geotechnical Engineering ASCE 112(1): 23-43.

Terzaghi, K. 1934. Large retaining wall tests - pressure of dry sand, Engineering News Record 112: 136-140.

Weissenbach, A. 1975. Baugruben; Teil II. Berechnungsgrundlagen. Berlin-Düsseldorf: Ernst \& Sohn. 